\title{
Emergence of Futuristic HRM in Perspective of Human - Cobot's Collaborative Functionality
}

\author{
Amit Saxena, Abhay Saxena, Rajeev Sharma, Mukesh Parashar
}

\begin{abstract}
Industry 4.0 buzzed out with a theme of "Smart Manufacturing for the Future". With the advent of Industry 5.0, the world of technology is registering a paradigm shift from Customization to Personalization. Advanced Manufacturing, Cognitive Computing, AI, Robotics, Collaborative Robots, where all these technologies altogether introduces Industry 5.0 onto the stage. Cobot's will be part of Human Resource Management. This Paper aims to visualize the Futuristic HRM and to understand the Collaborative Robots performance with Human HR's. In this study, we had discussed the possible issues related to human-robot collective functionality from the organizational and HRM perspective. We had also suggested the effective role of $\mathrm{HR}$ and Cobot $\mathrm{HR}$ while dealing with the human and machine employees. We believe that the issues identified in this study will pave way for many upcoming organizational robotics research studies.
\end{abstract}

Keywords: Cobot's, Human Relation Management (HRM), Human Cobot's functionality, HRM Processes

\section{INTRODUCTION}

The tidal waves of drastic transformations in the technological world are reorganizing the working scenario of the society, which is being classified as paradigm shift from Society 4.0 to Society 5.0. These technological advancements are not only revolutionizing the Industry and Manufacturing areas but also significantly influencing the Human Relations and Human Relation Management. The Human Relation Management mechanism is being remodeled with the interference of Technology, smoothening the way of introducing Industry 5.0. Human Relation Management emphasize upon the process of training employees, reaching out their needs, fostering a workplace culture and resolving the issues among them. The Remarkable saying explains, "You don't build a business, you build people and then people build the business". Similarly, the Human Relation Management is of great importance for the success of any Business.

\section{A. Changing Scenario And Hrm:}

The technological advancements are considerably impacting the Human Relation Management. It has radically

Manuscript received on June 04, 2021.

Revised Manuscript received on June 15, 2021.

Manuscript published on June 30, 2021.

* Correspondence Author

Mr. Amit Saxena*, Senior Manager, Department of Management, Birla Institute of Management Technology, Noida (U.P), India

Prof. Abhay Saxena, Dean, Department of Computer Science, Dev Sanskriti University, Haridwar (Uttarakhand), India

Prof. Rajeev Sharma, Assistant Professor, Department of Management, Birla Institute of Management Technology, Noida (U.P), India

Dr. Mukesh Parashar, Registrar, D. Y. Patil International University, Pune (Maharashtra), India.

(C) The Authors. Published by Blue Eyes Intelligence Engineering and Sciences Publication (BEIESP). This is an open access article under the CC BY-NC-ND license (http://creativecommons.org/licenses/by-nc-nd/4.0/) evolved the way Human Resource (HR) department used to deal with employees, the way of collecting data and analyzing the employee performance. The technological interventions are making the HR practices more efficient and systematic. The practices like online recruiting, communication with the employees, Data Analysis of employee performance, the established management of large amount of data and adoption of best security practices for the security of digital data, are show casing the exceptional technological presence in the changing scenario of development.

\section{B. Introducing Industry 5.0:}

Industry 5.0 or the Fifth Industrial Revolution is focused on the co-operation and collaboration between the Human Beings and the Machines. Industry 5.0 is an extended version of Industry 4.0 and likely to address the complex and expensive software, deployment challenges, and security leaks issues of Industry 4.0 more effectively. Industry 5.0 will introduce the Ideology that Humans would not be replaced by the Robots but rather they will be equipped by Cobots (The Collaborative Robots), that will establish a paradigm shift from Digitalization to Personalization, where the essence of 'Human Touch' would be felt. This Industrial Revolution will cause a paradigm shift to the development of Society 5.0. For fulfilling the objectives of Industry 5.0, the Cobots are going to play an essential role, which will enhance the Human and Machine interaction and push us towards the development of Advanced Human-Machine Interfaces. Cobots- The Collaborative Robots, are meant to operate in conjunction with, and in close proximity with human beings to perform their tasks.

\section{BACKGROUND}

\section{A. How Industry 5.0 Will Change The Hrm Perspective:}

The emergence of Industry 5.0 will influence HRM in two major aspects:

- Hiring of a Machine by Human being

- Hiring of a human being by Machine

\section{B. Hiring of a Machine (COBOT) by Human:}

The hiring of a machine would be a very new experience for a regular HR, because in conventional procedure, they used to hire human being right from lower to senior positions in the organizations, but Cobot's hiring will be a typical issue for them. What are the major issues that a HR will consider before hiring of a Cobot? The major focus will be on the following aspects:

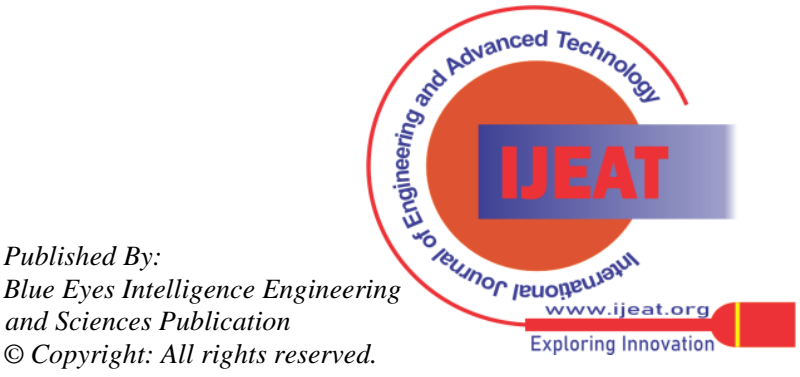


i. Data Set: The selection criteria, the routine questions and data set questions would be entirely different from the sets, which are being used for the hiring of human being.

ii.Knowledge Domain: The domain knowledge of Human Being has an upper edge as compare to Cobot, but the machine training \& testing with so many datasets is making the Cobot matchless ${ }^{[1] .}$ The dataset training with the help of ANN, SVM. \& other computational techniques had ensured the Cobot's learning is much better than human beings. ${ }^{[1]}$ iii. Industry 4.0 And Its Superiority

The question arises that whether Retirement Age or Expiry Date will be considered in the case of a COBOT or not? HR personnel while dealing with human beings scans the candidate's experience and then the compensation negotiations starts with the experienced candidate. However, while dealing with a Cobot, this will be a different scenario.

It will be matter of debate whether HRs will prefer fresh Cobots (untrained in working environment) or experienced Cobots (already engaged earlier in some other companies). An interesting question arise over here, "Whether the experienced Cobots are likely to apply of their own or they will be hired on referral basis".

\section{iv. Inbuilt Sepcialization:}

While dealing with screening phenomena of Cobot, the HR will look for data analytics capabilities of the machine. The HR will give Cobot a specific / typical data preset problem and the selection criteria will include response time, problem-solving attitude. However, the inbuilt specialization of Cobot will includes, the Data Analytics Capability, Application of ANN Techniques, Industry 4.0 qualities etc.

Good quality plagiarism software/ tool (Turnitin / iThenticate) will be used to check similarity that would not be more than $20 \%$ including reference section. In the case of exclusion of references, it should be less than $5 \%$.

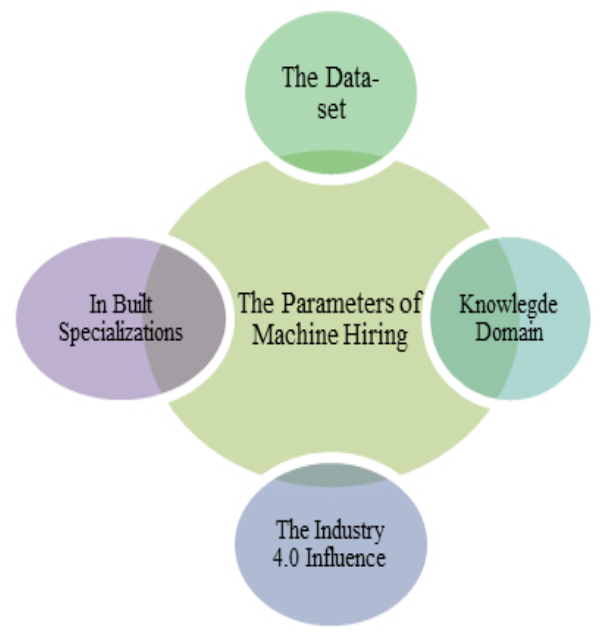

Fig.01 Hiring of a Machine by Humans

\section{Hiring of a Human Being by a Machine (COBOT):}

\section{i. Work Profile Analysis:}

In a typical HR selection process, the HR needs to scan the profile of candidates' time $\&$ again. This process is tedious $\&$ time consuming. However, if the Cobot is on the hiring seat, the available memory dataset will help the Cobot to scan the candidate capabilities once \& it will be stored for future reference. This will save the time \& space. Moreover, built in AI knowledge set will also help in screening the candidate

previous experience, interests, learning capability \& paned performance with work profile and can be used as and when required.

\section{ii. Knowledge Level Supremacy:}

Selection of an employee is base on the screening of the candidate \& Q/A is one of the important segment. However, if Cobot is on the hiring seat, there will be minimal chance of repetition of questions dataset. Moreover, based on the experience \& knowledge of the candidate, the question standard can be calibrated by Cobot.

\section{iii. Employees Referrals Will Fit In or Not:}

The Cobot's will understand employees' referral more easily; based on the analysis of previous referrals, \& the kind of employees. There will also be a check on number of referrals; quality vs quality analysis of referral candidates. However, the candidate will find a hard time during selection process through such strict processes.

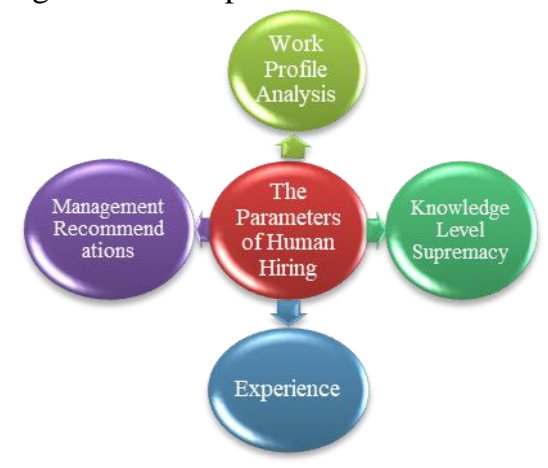

Fig.02 Hiring of a Human Being by a Machine

\section{METHODOLOGY}

The Methodology introduces the perspective of Human Relation Management (HRM) requirements for futuristic hiring. The diagram Fig. no 2. had shown that how the effective communication between the Cobots and Human Being will be established.

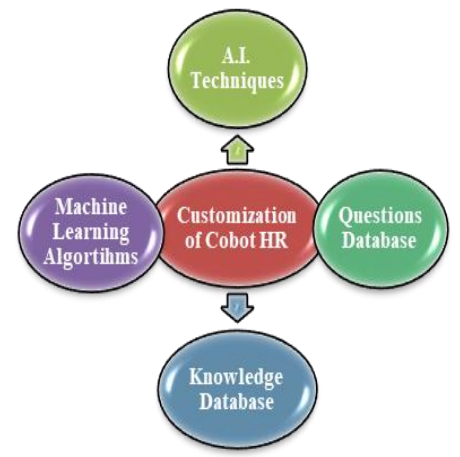

Fig.3 the Dimensions of Cobot HR Customization

From traditional industrial robotic systems to collaborative robots (Cobots), they rely on sensors that generate increasingly massive volumes of highly varied data and for the processing of the same, the AI techniques are far better.

Published By:

Blue Eyes Intelligence Engineering and Sciences Publication

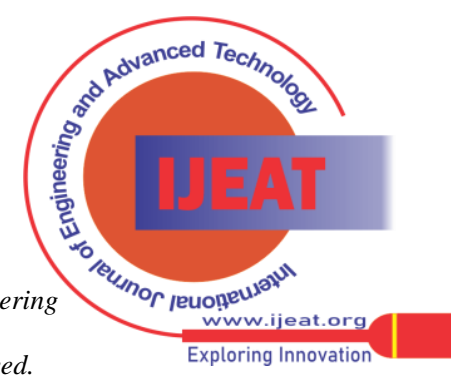


The common belief is that robots are smarter than human beings; rather they have capability of handling significantly more variables than humans. A human being can handle 10 to 15 variables at a time while Machine Learning (ML) algorithms handle thousands of variables simultaneously. Moreover, ML algorithms can be design to slice and dice information, to identify hierarchical layers of information, create outlines, and synthesize this information to make decisions in a microsecond or less. Thus, ML algorithm can ease our hiring process.

\section{THE EFECTIVENESS OF COBOT REFORMATION}

The advancements of technology with Cobot and Human Interaction will add up new values to the product manufacturing with focus on personalization, leading effectiveness in the workflow and industrial space. The following aspects and parameters will prove that the Cobot HR will be more effective in the Era of Industry 5.0.

\section{i. Future Trends and Technology Prediction:}

Cobot's can make the organization more successful and developed by suggesting the trends to be adapted. Cobot HR would be equipped with Prediction Analysis Tool, which would result in scaling the growth expectancy of the organization.

Cobot HR can easily forecast the sales, marketing prices, future sales trends and production cycles. As they are equipped with Artificial Intelligence Techniques, Machine Learning Algorithms will help them to analyze and predict the trends based on the feed data sets and available domain knowledge.

\section{ii. Scanning of the Market Sentiments:}

The Cobot HR would be smart enough to watch out the market trends, technologies and equipped with the power to analyze and predict the marketing sentiments. It will be a pathway of organization to smartly invest and expand their vision, with the help of accuracy and precision of marketing sentiment analysis by the Cobot HR. The Real Time Sentiment Analysis and Market Prediction is the key for the Successful Organization. This is equipped with Natural Language Processing (NLP) and ML to interpret and classify market sentiments into subjective Data.

\section{iii. Big Data Analytics:}

The real wealth in today's technological world is the Data. The strength and power of any Organization or even of an individual is based upon the Data and Data Management. The Organizations are based on the Data and relevant information. The Cobot HR can easily deal with the Inflow and Outflow of data, through the prominent Big Data Analytical Market Tools like Tableau, Casssandra, SiSense, Zoho, Splunk.

The key segments of HR analytics are:

- Hire, Retain, \& Develop the best talent.

- Workforce analytics

- Talent Analytics

The Role of Cobot's HR using the HR analytics would forecast the workforce management problem in combination with better workforce planning, Talent acquisition \& HR development.

\section{iv. Human Behavior Analysis:}

Human behavior is one of the most unpredicted aspect of human being but also human behavior is key to unlock the many hidden potential of individuals. The range of factors that influence the Human Behavior are right from the workplace to the performance, relating with juniors \& seniors to the productivity. The role of Cobot HR is crucial in analyzing the human behavior. The biasness for the human being will be the primary key.

The emotion analysis, the performance rating; the rationale behavior; lack of commitment, sense of insecurity, burn out stress syndrome, underutilization are the key aspects where Cobot HR can easily figure out with the study of human behavior. The Cobot's HR will also be dealing with Human Machine behavior. There are many analytical tools available in the market, which are keeping track of behavioral analytics[11].

\section{v. Prediction and Analysis of Individual/ Team/ Organization Productivity:}

Organization success depends on the performance \& productivity. Usually organization are using prediction tools for performance prediction, mostly it is based on the individual capability \& experience.

The available data sets of individuals like his/ her daily, weekly, monthly \& yearly performance, learning capacity: effectiveness, communication, deliverance will help the Cobot's HR to precisely predict the human capacity \& performance. The collective efforts of the individuals, the team spirit, shared vision \& functionality will help the Cobot's HR to workout with the prediction of team \& further growth of the organization.

\section{THE COBOTS ON STAGE:}

The A.I. is making its vital presence in recruitments. Recruitment Chatbot is working as a HR Manager Dream Assistant (Ceipal). In a comprehensive manner, the chatbot can handle multiple clients simultaneously. The popular Chabot's are providing valuable information related with recruitment like talent acquisition, candidate ranking, on boarding, learning \& training etc.

Some of the popular chatbots are:
i. XOR
ii. Mya
iii. Brazen
iv. Olivia
v. Espressive
vi. Talkpush
vii. ALLYO

Allyo has participated in 10 million conversation \& popularly used by FedEx. Olivia is using ROBUST Tech. XOR is owning $>85 \%$ increase in number of applications. Mya has 79 \% reduction in time of interview. [13].

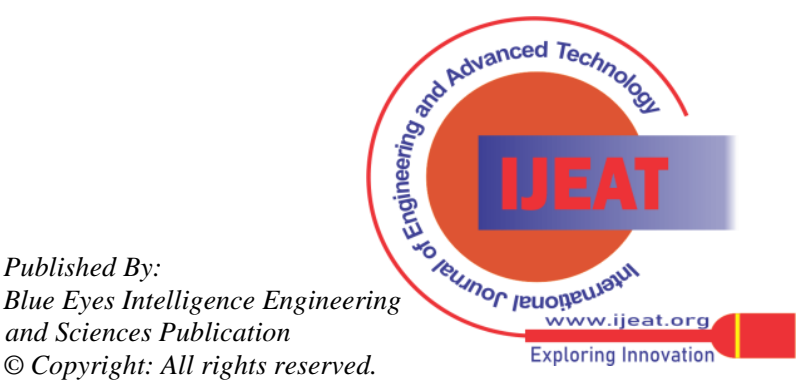




\section{WILL THE EMERGENCE OF HR COBOT'S WILL CREATE A THREAT TO EXISTING HR'S?}

The emergence of Industry 5.0 had brought the Human HR and Cobot's more closely. The collaboration started with the emergence of traditional Robot's and it looks in both of them will work more on responsive collaboration in future Table 1. The IFR (International Federation of Robotics) had defined the five level of Human being collaboration with Robots. (Shweta 2020)

\section{Table 1.Five level of Human being collaboration with} Robots

\begin{tabular}{|c|c|c|c|}
\hline A & $\begin{array}{c}\text { Lower } \\
\text { Level }\end{array}$ & $\begin{array}{c}\text { Traditional } \\
\text { Robot }\end{array}$ & $\begin{array}{c}\text { Work in its own } \\
\text { workplace }\end{array}$ \\
\hline B & $\begin{array}{c}\text { Second } \\
\text { Level }\end{array}$ & $\begin{array}{c}\text { Coexistence } \\
\text { Collaboration }\end{array}$ & $\begin{array}{c}\text { Not caged but the } \\
\text { workplace is not shared } \\
\text { with human }\end{array}$ \\
\hline C & $\begin{array}{c}\text { Third } \\
\text { Level }\end{array}$ & $\begin{array}{c}\text { Sequential } \\
\text { Collaboration }\end{array}$ & $\begin{array}{c}\text { Robot \& Human share } \\
\text { the same workplace \& } \\
\text { work in sequential } \\
\text { manner }\end{array}$ \\
\hline D & $\begin{array}{c}\text { Fourth } \\
\text { Level }\end{array}$ & $\begin{array}{c}\text { Cooperation } \\
\text { Collaboration }\end{array}$ & $\begin{array}{c}\text { Robot \& Worker work } \\
\text { on same part } \\
\text { simultaneously }\end{array}$ \\
\hline E & $\begin{array}{c}\text { Fifth } \\
\text { Level }\end{array}$ & $\begin{array}{c}\text { Responsive } \\
\text { Collaboration }\end{array}$ & $\begin{array}{c}\text { Robot's response on } \\
\text { real time to the } \\
\text { worker's movement }\end{array}$ \\
\hline
\end{tabular}

Cobot's presence in organization will surely leads towards more jobs. The tedious jobs like packaging, palletizing, control of the quality \& quantity and machine tending jobs can be easily taken care by Cobot's so that human being can focus on human centric work.

We can easily figure it out from the IFR classification that robotic process automation is now more on intelligent robotic process automation (IRPA). If current resume classification is (RPA) then IRPA is predicting the human potential along with the resume classification. The cobot's HR are likely to support the human HR's. Most of the companies are using Cobot's for:

- To increase the productivity

- To look into the wellbeing of employees

- To ensure the product/service accuracy.

- To ensure the employee's retention

- Ergonomics Improvisation

The automation started from man Vs machine but now with the emergence of cooperation \& responsive collaboration, the paradigm have been shifted to man and machine.

We herewith proposed the option of cooperation \& responsive collaboration of HR's \& Cobot's HR. Think of a situation where tedious HR's could be free from routine job's to work more efficiently on psychological wellbeing of employees. Some of the major factors that HR and Cobot HR can collectively handle into an organization is list out into the table 1.

\begin{tabular}{|c|c|c|}
\hline & $\begin{array}{l}\text { Human } \\
\text { Employee }\end{array}$ & Machine Employee \\
\hline $\begin{array}{l}\text { Human } \\
\text { HR }\end{array}$ & $\begin{array}{c}\text { HRM } \\
\text { Social Well Being } \\
\text { Promotion } \\
\text { Performance } \\
\text { Appraisal }\end{array}$ & $\begin{array}{c}\text { Productivity } \\
\text { Quantitative Work } \\
\text { Responsiveness } \\
\text { Accuracy \& Precision } \\
\text { Knowledge Data Set }\end{array}$ \\
\hline $\begin{array}{l}\text { Cobot } \\
\text { HR }\end{array}$ & $\begin{array}{l}\text { Mood analysis } \\
\text { Performance } \\
\text { Factor } \\
\text { Retention } \\
\text { Capacity } \\
\text { Out of box } \\
\text { suggestion } \\
\text { Unbiased support } \\
\text { talent acquisition }\end{array}$ & $\begin{array}{c}\text { Future trends \& } \\
\text { Training } \\
\text { Market sentiments } \\
\text { analysis } \\
\text { Previous } \\
\text { performance } \\
\text { Customization \& } \\
\text { specialization }\end{array}$ \\
\hline
\end{tabular}

It is a bit clear from the table 2 that human HR \& Cobot HR collectively can make a big difference in any organization. Let's see all the permutations one by one.

Scene 1: When a Human HR is likely to hire Human being as an employee for the organization. It is a common scenario where the Human HR's emphasis is on the social wellbeing of the employee. The performance is the key aspect of the employee promotion and appraisal.

Scene 2: When a Human HR is likely to hire a Machine as an employee for the organization. The Emphasis will be on the Machine productivity (proven record of accomplishment), Responsiveness, accuracy and precision (based on the new scenario, instructions) and the knowledge data sets preowned by the Machine employee.

Scene 3: When a Cobot HR is likely to hire a Human being as an employee for the organization. The Cobot HR will look for the Human being's performance, mood syndrome if any; novelty of the ideas by the prospective employee and the decision will be free from any biasness.

Scene 4: When a Cobot HR is likely to hire a Machine as an employee for the organization. This will be an interesting scenario where the Cobot HR will emphasis on machines adaptability related with future trends and training is concern. The Cobot HR will also look for the machine's previous performance in the other organization along with the customization and specialization of the machine.

In brief, the technical support of Cobot HR will surely raise the performance of human employees whereas the human HR will surely help the machine workers to raise their domain knowledge, like human being. The Futuristic HRM is likely to be a Human Cobot's collaborative efforts where both Human and Cobot's are likely to be interdependent and cohesively perform the HRM activities more smartly and effectively.

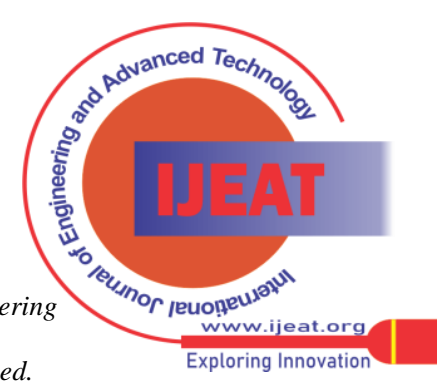




\section{CONCLUSION}

The industry 5.0 will surely bring new wave of productivity and personalization into the working environment of organization. The machine is not likely to replace the human being. Rather if machine and human being work together in collaborative mode then it will surely make a huge difference into the organization's outcome. The Futuristic HRM is likely to be a combination of Machine and Human being. The emergence of Cobot HR will surely help the existing Human HR to deal their responsibilities more effectively. Cobot HR will overtake the tedious, boring and routine tasks so that Human HR's can handle specialized and human centric work. The automation journey initiated the debate of Man vs Machine but now with the emergence of co-operation \& responsive collaboration it is more on mutual dependency and the changed scenario is Man with Machine. The Futuristic HRM is likely to take the organization to new heights and horizons in future. All the issues discussed are subjects for further discussion, investigation, experimentation, in short for a wide range of research.

\section{REFERENCES}

1. www.the robot report.com/5-things-robots-better-human

2. Demir, Kadir Alpaslan (2017) "Research Questions in Roboethics." Mugla Journal of Science and Technology 3 (2), 2017: 160-165.

3. Sheridan, Thomas B., and William L. Verplank (1978) "Human and Computer Control of Undersea Teleoperators." Man-Machine Systems Laboratory Report, MIT, Cambridge, USA, 1978.

4. Bekey, George A. (2005) "Autonomous robots: From Biological Inspiration to Implementation and Control" Cambridge, USA, MIT Press.

5. Ray, Céline, Francesco Mondada, and Roland Siegwart (2008) "What do people expect from robots?" 2008 IEEE/RSJ International Conference on Intelligent Robots and Systems, 2008: 3816-3821.

6. Cormier, Derek, Gem Newman, Nakane, Masayuki, James E. Young, and Stephane Durocher (2013) "Would you do as a robot commands? An obedience study for human-robot interaction" International Conference on Human-Agent Interaction.

7. Bagdasarov, Zhanna, April A. Martin, M. Ronald Buckley (2018) "Working with robots: Organizational Considerations." Organizational Dynamics, 2018: https://doi.org/10.1016/j.orgdyn.2018.09.002

8. Maier, A., and Student. D. (2015) "Industrie 4.0 - Der Große Selbstbetrug." Manager Magazin, 13.02.2015, http://www.managermagazin.de/magazin/artikel/digitale-revolutionind ustrie-4-0-ueberfordert-deutschen-mittelstand-a-1015724.html

9. Sachsenmeier, Peter (2016) "Industry 5.0-The Relevance and Implications of Bionics and Synthetic Biology.” Engineering, 2, 2016: 225-229.

10. European Commission (2012) "Innovating for Sustainable Growth - A Bioeconomy for Europe." Retrieved from https://ec.europa.eu/research/bioeconomy/pdf/official-strategy_en.pdf

11. www.appcues.com/blog/product-behavioral-analytics-tool-guide

12. Elvis, Martin, and Tony Milligan (2019) "How much of the solar system should we leave as wilderness?" Acta Astronautica, 2019: https://doi.org/10.1016/j.actaastro.2019.03.014

13. https://www.ere.net/chatbots-anti-ghosting-magic/

14. Briggs, Gordon, and Matthias Scheutz.(2014) "How Robots Can Affect Human Behavior: Investigating The Effects of Robotic Displays of Protest and Distress." International Journal of Social Robotics 6 (3), 2014: 343-355.

15. Schütte, G. (2018) "What kind of innovation policy does the bioeconomy need?" New Biotechnology 40 (A), 2018: 82-86.

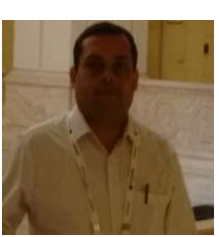

\section{AUTHOR PROFILE}

Mr. Amit Saxena, is currently associated with the Birla Institute of Management Technology (BIMTECH), Greater Noida. He works in the area of Human Resources and People Management. He holds a Post Graduate Degree in Management. He has attended many national and international level conferences, workshops, and seminars. Also has published 4 research papers in reputed journals.

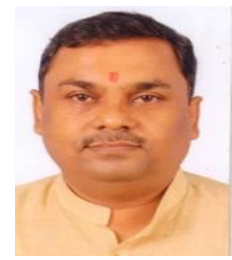

Prof. Abhay Saxena, Dean (School of Technology, Management \& Communication) at Dev Sanskriti Vishwaviidyalya, Hardwar, India. Doctoral Degree in Computer Science, Artificial Neural Networks (ANN). Visiting Professor at 3 International University, Academic and industry experience of 26 years. Recently book is An Internet of things futuristic computing. Authored 8 Books Completed 3 Govt. funded projects completed. Likely to take Joint Research publication, Project along with Visiting Professorship with International Peers.

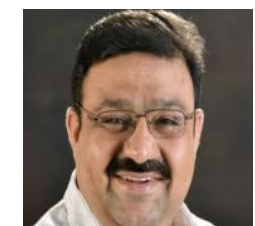

Prof. Rajeev Sharma, Presently is Assistant professor at the Birla Institute of Management Technology, Greater Noida. He works in the area of Operations and Decision Sciences. His area of Interest is Supply Chains and logistics, with other areas as emerging technologies, entrepreneurship, and sustainability. He holds a degree in Commerce and is an Associate cost management accountant.

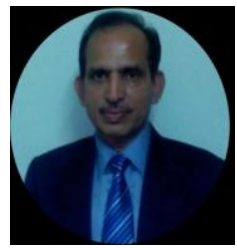

Dr. Mukesh Parashar, Ph.D., MBA, M.Sc., PGDAPR, DME 16 years of experience with the engineering industry in various fields like QC, Purchase, Sales. Settled more than 1500 claims of MOTOR and ENGINEERING as impaneled Surveyor \& Loss Assessor with National Insurance Co Ltd, United Insurance C. Ltd.., and New India Assurance Co. Ltd. Worked as Training \& Placement Officer, Headed Admission Cell of an internationally reputed engineering institute for 10 years. Serving as Registrar of State Private Universities for the past 8 years. Whole-time president of Shri Mehandipur Balaji Shiksha evam Kalaa Vikas Samiti, devoted to the development of women and child education. Conducted more than 100 seminars to create awareness about higher and technical education, selection of appropriate area of studies, University and college in tribal areas like Dhar, Jhabua, Alirajpur, etc. of western Madhya Pradesh. Attended many national and international level conferences, workshops, and seminars. Published 7 research papers in reputed international journals. Certified lead auditor for ISO 9000:2008 and expertise in NBA, NAAC, and NIRF accreditation and ranking awards.

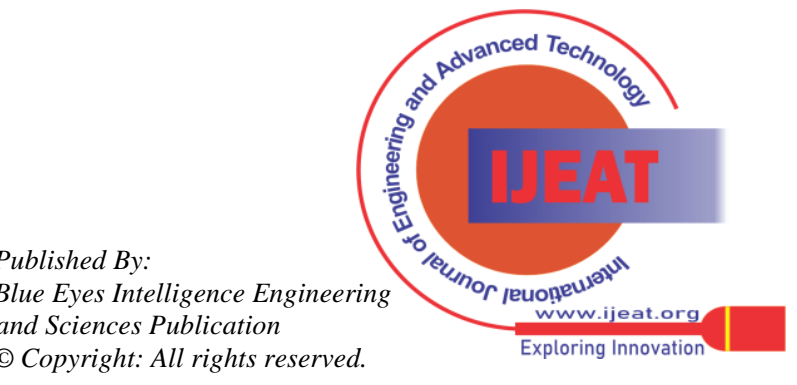
(c) Copyright: All rights reserved.

$$
\text { Exploring innovation }
$$

